\title{
Richard Morton (1637-98) and his Phthisiologia
}

\author{
RY KEERS \\ From Port Erin, Isle of Man
}

ABSTRACT Richard Morton was one of the outstanding physicians of the seventeenth century. After graduating BA at Oxford he elected to enter the Church, becoming ultimately Vicar of Kinver in Staffordshire. On the Restoration he found himself unable to comply with the requirements of the Act of Uniformity and was ousted from his Staffordshire living. He disappeared for eight years but reappeared in 1670 when, on the sponsorship of the Prince of Orange, the degree of MD was conferred on him by the University of Oxford. He set up in practice in London and was elected a Fellow of the Royal College of Physicians in 1678. He has left a lasting memorial in the form of his book Phthisiologia which deals with all aspects of phthisis, the word being interpreted in its widest sense to denote any disease associated with wasting. It is not known where Morton obtained his medical education nor is there anything in his writings to indicate where he spent the eight years between 1662 and 1670. It is suggested that he may have been in Holland for part of those years attending the University of Leyden and making the acquaintance of the Prince of Orange whose patronage was to prove so useful at Oxford in 1670 .

Pulmonary tuberculosis was rife in seventeenth century England, a period when Locke estimated in his De Phthisi that $20 \%$ of the deaths occurring in London were caused by that one disease. ${ }^{1}$ Small wonder therefore that it loomed large in the minds and practices of the group of outstanding physicians which the century was to produce. Christopher Bennet (1617-55) the first of these, was himself a victim of tuberculosis, ${ }^{2}$ a circumstance which he considered made him the authority on the subject and led him into the making of dogmatic statements, some of which were hardly justified by his supporting evidence. Hard on his heels came Thomas Willis (1621-75), appointed Sedlian Professor of Natural Philosophy at Oxford in June 1660 and remembered in history for the Circle of Willis. In his Practise of Physick, published some years after his death, he devoted one chapter to tuberculosis "Of a Phthisis properly so called or of a Consumption arising from a Fault of the Lungs" which in the text he defines as "a withering away of the whole body from an ill formation of the Lungs." 3 Thomas Sydenham (1624-89) confined his writing on tuberculosis to a brief communication De Phthisi which would probably be of little importance in medical history were it not for its insistence on what Sydenham regarded as a sovereign remedy-horseriding-of which he wrote with great enthusiasm.

As far as tuberculosis is concerned, however, the outstanding figure of the century was Richard Morton (1637-98) (figure) who has left a memorial in the form of his book Phthisiologia, the Latin text of which was originally published in London in 1689.

Morton had come into medicine fortuitously for it had not been his first choice when selecting a career. Instead he had elected to follow in the footsteps of his father, Robert Morton, who was the Minister of Bewdley Chapel in Worcestershire from 1635 to 1646.4 In preparation for entering the church, he matriculated at Oxford as a commoner of Magdalen Hall in 1653, subsequently changing to New College where he graduated BA in January 1656. Shortly after graduation he became chaplain to his college, an appointment which he held for some two years when he relinquished it to become chaplain to the family of one Philip Foley of Prestwood in Staffordshire who also assigned to him the living of Kinver in the same county. He proceeded MA in 1659 and settled down to pursue the peaceful life of a country vicar, but his peace was soon to be shattered by the events which followed the Restoration. Under the Commonwealth Morton had embraced nonconformist principles and at the Restoration he became one of those Protestant Dissenters whose consciences prohibited their subscribing to the Act of Uniformity which, in 1662, had restored the Prayer Book. This restoration of the Prayer Book had the effect of turning adrift some 2000 clergy who could not give their "unfeigned consent and assent" to everything the book contained and Morton was thus ousted from his living and forbidden to practise his religious vocation again. 


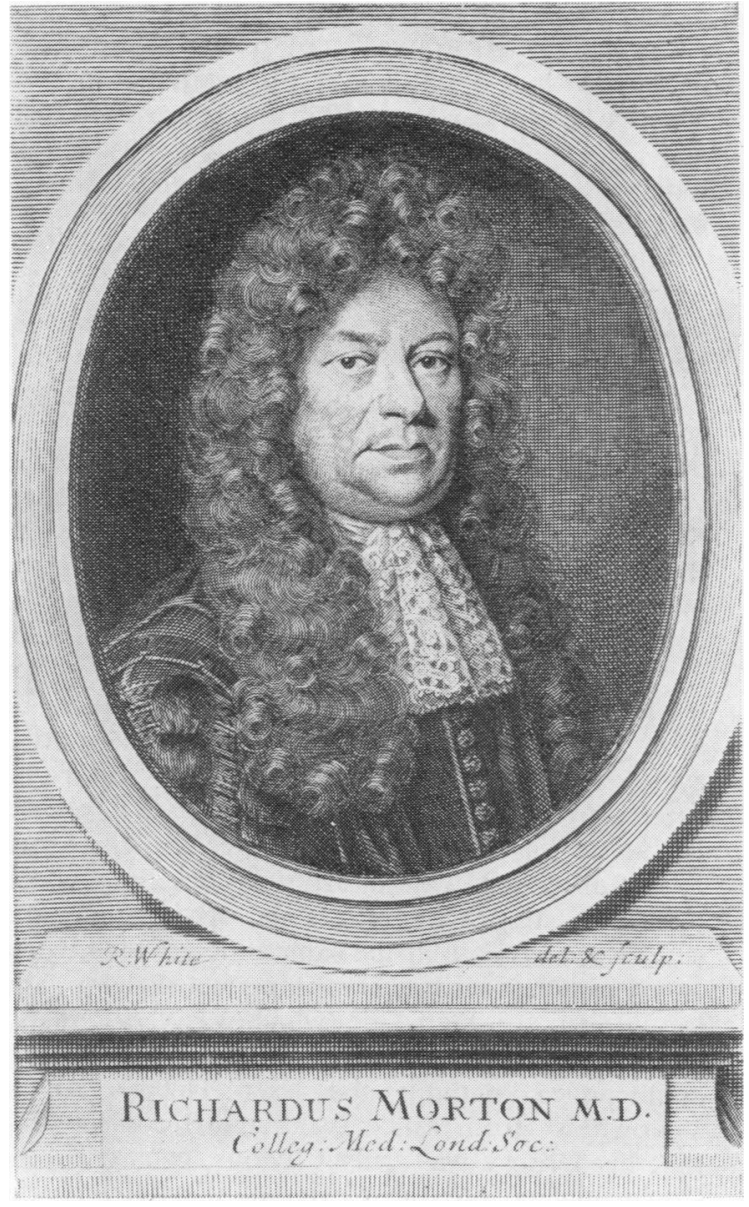

It is at this point that we come to the great mystery in his life for literally nothing is known with certainty of his movements or whereabouts during the eight years which elapsed between his departure from Kinver in 1662 until his appearance on the medical scene in 1670 when the degree of MD was conferred upon him by the University of Oxford. He was nominated for this distinction by the Prince of Orange who attended a ceremony at Oxford that year on the occasion of his first visit to England to which he had come in the hope of collecting a debt owed him by Charles II. ${ }^{5}$ There is no record of where Morton lived during those eight missing years or of how he occupied himself but clearly he must have made the acquaintance of the Prince of Orange during that period and since the Prince did not visit England until 1670 Morton must have met him in Holland. What he was doing in that country is a matter for speculation.

From 1670 onwards the cloud of mystery which
Figure Richard Morton (1637-98). Engraving by $R$ White, 1654. By courtesy of the Wellcome Trustees. had enveloped Morton during those eight years seemed no longer to matter for his life thereafter was an open book. Armed with his Oxford MD he lost no time in settling down to practise in London and established himself in a house in Grey Friar's Court, Newgate Street. His troubles, however, were not completely resolved. He was admitted a candidate of the College of Physicians in March 1675 and became a Fellow in December 1678. But in 1686 his was one of four names of Fellows omitted from the list which accompanied the renewal of the College Charter by James II, ${ }^{5}$ allegedly because the King judged him to be politically unreliable in view of his acceptance of the patronage of the Prince of Orange. A period of three years followed during which he was unable to take part in any of the college debates or activities but he was restored to his fellowship in 1689 after the accession of William and Mary. In 1689 his troubles were over and Richard Morton progressed to the highest ranks of his profession. He was a censor of 
the College in 1690,1691, and 1697 and was also appointed a physician-in-ordinary to the King. In addition he left behind him work of an enduring nature, and it is by his Phthisiologia that he is remembered, a book devoted solely to the subject of phthisis, the Latin text of which was originally published in London in 1689. Editions in English followed in 1719 and 1720 and it is from the second of these that the passages quoted here have been abstracted. There were also continental editionsfrom Frankfurt in 1690, Ulm in 1714, and Helmstad in 1780 , dates which indicate how well the book maintained its authority over a century.

While the term phthisis came in course of time to be applied exclusively to pulmonary tuberculosis it had, in Morton's day, a much wider connotation and was used to describe any disease characterised by wasting. This wider interpretation led him to divide his Pthisiologia into three sections. The first, in the author's own words, treats "Of consumption in general, and particularly of a Consumption proceeding from the whole Habit of the Body, or an Atrophy, both that which is Nervous, and that which is caused by Evacuations." Throughout the book he employs the term "consumption" freely and obviously regards it as an acceptable English translation of the more classical "phthisis". In this first section he included, among others, chapters on such items as a "Consumption from Bleeding", a "Consumption happening to Nurses, from the giving of Suck beyond what their strength will allow", a "Consumption caused by profuse sweats" a "Consumption proceeding from a Dropsy", and a "Consumption proceeding from Apostemes and large Ulcers". Clearly this is a somewhat heterogeneous collection of pathology, only a few of the case histories with which the text is illustrated suggesting true pulmonary tuberculosis; nevertheless this section of the book is of great interest by providing an opportunity to assess Morton's competence as an all-round physician. His clinical account of a case "proceeding from Apostemes and large Ulcers" deals with the problem of a woman in poor circumstances who complained of long-standing abdominal pain and loss of appetite" even to the degree of a Marasmus with an intolerable Thirst, a continual weakness, Want of Appetite and Want of Rest."6 She was ultimately seen by Morton who "observing the Parts of the Loins to be swell'd and to resist a Pressure, and perceiving the Fluctuation of purulent matter under one finger when we pressed it-I ordered that after the Application of a Caustick, the Tumour should be opened in a convenient Place: which was no sooner done, but a great Quantity, first of clear then purulent matter, and a great number of little Bags filled with a very clear Water, at least five hundred, gushed out with a great force". Even though Morton did not realise that he was dealing with a hydatid cyst his treatment proved effective for "the Ulcer within the space of a Year and a half (which we did designedly keep open so long with a Silver Tent that was hollow) was at length perfectly healed".

Morton illustrated a further chapter on "A Consumption proceeding from a Dropsy" by the description of the problem presented by a 2-year-old boy, the son of one Thomas Lechmore who "fell into an Inflammation of his lungs upon taking of cold and was treated very ill by an Apothecary, who had omitted Bleeding and other things, that were very requisite to a true and skilful method of cure. But at length I and my famous colleague Dr. Croon, though we were called in late, recovered him in some measure by taking away some Blood-But yet he continued sickly with a Cough and difficulty of breathing, for the space of a Twelve-month at least, from which Time the poor child began to be seized with a Hecktick Fever, which intermitted every day and indeed came upon him by uncertain Intervals for a whole Year, even to his dying Day. But at the very beginning of the Fever his Belly began to be distended with a dropsical Swelling which increased strangely every day; his Cough and shortness of Breath at the same time growing worse -but yet when his body was a perfect skeleton, and the Dropsy at a high Tide (which was very remarkable) he had a brisk and healthful Look and a lovely countenance, without the least Tincture of a Yellowness-from which I did rightly conjecturethat his Dropsy was truly Chylous, caused by the Chyle flowing into the Cavity of the Belly by the Lacteal Vessels, which were broke by some Accident, and that the Consumption which accompanied it, was not a true Consumption of the Lungs, but such as proceeded merely from an Inanition, that is, the draining of the due Nutritious Juice out of the Lacteal Vessels, upon some rupture that had been made in them-For in Tapping of the Child's Belly, whilst he was yet alive we took out several Pints of milky Chyle-But when we opened the body after he was dead, we found for all the Difficulty of Breathing and long Cough he had, the Lungs themselves sound, without any Distemper, but only that in the hinder part near the wind-pipe there appeared a great many Glands, and these pretty large and hard, which made a hard and very considerable Pressure upon the Chyle-duct itself, almost at that Part where it arrives at the Subclavian Vein; and they were of so great a Weight and Bulk, that it seemed very difficult, if not plainly impossible, for the Chyle to pass into the Blood, by reason of the Pressure they had made upon the Duct, which had streightened it, 
as if it had tied with a String". From these observations Morton deduced that "the thin Lacteal Vessels which are in the Belly-being distended beyond their Tone did at length break, so threw the Chyle - as it were in a continued Stream, into the Cavity of the Belly." 6 These findings are a remarkable tribute to his powers of observation and, even if all his deductions were not entirely justified he had, nevertheless, given prolonged and serious thought to what he had seen and his thinking led him to a number of conclusions. First, that these tubercles or tumifyed Glands of the Lungs did at first proceed from the ill method of curing the Inflammation of his Lungs, that is, for want of timely Bleeding and Expectoration. Secondly, that as the troublesome and dry cough was caused by the Constriction of the Vessels of the Lungs-by these Swellings, so the Difficulty of breathing proceeded from the Pressure of the extravasated Chyle below the Midriff. Thirdly, that the Consumption was not a true Consumption of the Lungs-but-did really proceed from that Chylous Dropsy from which that Nutritious Juice, which ought to have been employed for the Reparation of the Blood-was continually subtracted and carried another way. Fourthly, that this Dropsy did proceed from a rupture of the small Lacteal Vessels that are in the Belly; and, lastly, that this Rupture of the small Lacteal Vessels was caused by that continual Pressure, which the Swellings in the Lungs had made upon the upper Part of the Chyle-duct."

The second section of Phthisiologia is entitled "Of an Original Consumption of the Lungs" which is defined thus: "Consumption of the Lungs is a Consumption of the whole Body with a Fever, proceeding first from an ill Affection, and at length an Exulceration of the Lungs: which, indeed, is the most famous Consumption-and I shall now speak more largely of it."6

His account opens with a chapter "Of the Causes of an Original Consumption" this being a mélange of what he regards as initiating factors which he lists under a series of headings: (1) the Stopping of Evacuations; (2) Troublesome Passions of the Mind (including too much Thinking); (3) Intemperance in Eating and Drinking; (4) Want of due Exercise; (5) Night Studies; (6) an Ill Air and, in particular, "that which is filled with the Smoak of Coals"; (7) an Hereditary Disposition from the Parents; (8) an Ill formation of the Breast whether it be Natural or Accidental; (9) Infection "for this Distemper-like a contagious Fever, does infect those that lie with the sick Person with a certain Taint"; (10) Chalky Stones "that are preternaturally bred in the Lungs"; (11) Also some particular Diseases which "corrupt or overthrow the Nature of the Blood and Spirits do occasion this Distemper". It is interesting to note that Morton even with Villemin and Koch still 150 years away recognised that infection might play some part in the initiation of the disease.

In his second chapter he discusses the degrees of an original consumption of the lungs and the signs which give warning of it, together with "what we are directed to do in order to prevent it". In this latter section he utters some words of wisdom "Therefore in the preventing of a Consumption (which is much easier than the cure of it) the great Business, whilst the Patients remain in this sickly Condition is to take all possible Care that no Error be committed in those six things, which we call not natural. For in this so slippery a State of Health, they are wont upon every little Occasion of this Nature to fall headlong into a Fatal Consumption." He then makes his six points cautioning prudence in the choice and amount of food and drink, the desirability of sleeping in the early part of the night and avoiding sleeping too long in the morning, the need each day for some moderate exercise, the avoidance of strong purgatives the cultivation of a contented mind, and the enjoyment of "an open, fresh, kindly Air and such as is free from the Smoak of coals". In concluding this chapter he gives utterance to a heartfelt cry, a cry that has been re-echoing down the ages. "But alas! Physicians have very seldom an Occasion to give their Advice about preventing this Distemper-the sick Persons seldom imploring Aesculapius's Help, before the Distemper has run on so far as to be a fatal Case and then they in vain expect Miracles from the Art of Physick, when it is more convenient for them to have the good Counsel of a Minister about the future Salvation of their Souls, and the Advice of a lawyer about making their last Will."6

He then passes on to discuss diagnosis which he does at considerable length by detailing the symptoms which he has noted and endeavouring to relate these symptoms to the findings at his numerous postmortem examinations. And here he gets carried away by his study of the tubercles in the lung: "Yea, when I consider with myself, how often in one Year there is Cause enough ministered for producing these Swellings, even to those that are wont to observe the strictest Rules of Living, I cannot sufficiently admire that anyone at least after he comes to the Flower of his Youth can die without a Touch of Consumption."6

His chapter on prognosis is naturally somewhat gloomy though not universally so for he does admit to the possibility of improvement and even in some cases, of cure. He draws a clear distinction between the acute and the chronic case and speaks of a palliative cure: "So long as those swellings can but 
be kept from an Inflammation and Exulceration by Balsamick and other such-like Medicines. By which means it comes to pass that the Patient, though he is sickly and subject to Fevers, even upon every little Occasion, yet is able to do his ordinary Business and many times lives to grow old." $\mathrm{He}$ was also well aware of the propensity of the disease to relapse and warned that "Every Consumption, though it be cured, is apt to return and he that has once been in a Consumption, unless he governs himself very regularly, falls back into the same condition, even upon the least Occasion-Yea, moreover even after the most perfect Cure of a Consumption, there is Reason to suspect that there are some crude Tubercles which at length may, by often meeting with an Occasion, be inflamed, and ripen into Apostemes and so at last become Ulcers." 6

His chapters on treatment are long and contain a sound basis of common sense as indicated by his instructions on general management. He stresses the need for an adequate diet, an environment free from fog and smoke, and the desirability of ensuring a moderate amount of exercise. All Morton's therapeutic dicta are in their humanity and thoughtful care in striking contrast to the regimen of copious bleeding and semi-starvation inflicted upon the dying poet John Keats by a later generation of physicians. He prescribes freely but his prescriptions are the least important part of his writings consisting as they do of lists of multiple ingredients of uncertain or negligible efficacy culled from the apothecary or the herbalist with a few redolent even of the witch's cauldron. As a humane and kindly physician he employed opium freely to relieve the more distressing symptoms such as the abdominal pain and diarrhoea associated with a terminal intestinal tuberculosis.

In the third section of Phthisiologia Morton passes on to consider what he terms "Symptomatical Consumption of the Lungs which is caused by and depends upon some other preceding Disease". This he regards as the most common of all consumptions and he estimates that he sees five such cases for every one of the "Original Consumptions" which come his way. As examples of the causative preceding diseases he cites "Crapulous and Intermitting Fevers, from the Small-Pox, Measles, Scarlet Fever, a Pleuresie, Peripneumony, Melancholy and Hysterick Affections; from the King's Evil, Scurvy, Green Sickness, Asthma, Spitting of Blood, Stones in the Lungs and sometimes also in the Kidneys and Bladder-" and goes on to warn his readers that, in dealing with symptomatical consumption, they must pay due regard to the treatment of the precipitating diseases as well as of the consumption itself. As may be surmised from his comprehensive list of precipitating conditions many, though by no means all, of the accompanying consumptions were nontuberculous and some of the case histories with which he illustrates his chapters make interesting reading. Thus in the chapter headed "Of a Consumption caused by Stones bred in the Lungs and by things slipt down into them from without" he describes the problem of "a young man, living near Cripple-Gate, that was strong and in every way sound in his Entrails, as he was doing something at his trade of whiting, by which he got a convenient livelihood, by chance with laughing heartily let three Nails, which he held in his Mouth for his use, go down through his Wind-pipe into his Lungs. Whereupon being seized with a most violent cough and continued tickling, he fell into a very great spitting of blood. From which symptom I know not by what means, he got himself free. But this is most certain, that though those Nails never came up again-yet the young man was very well for the space of several months, following his Employment as before-but, upon his Wedding Day, whether from his more liberal drinking of Wine or from his dancing too much (with which the nails that before lay unmoved, and as it were buried in the substance of the lungs, were stirred again) the poor Bridegroom in the Evening was taken with dreadful Spasms and a most acute pain in his Breast and Side, and withal a difficulty of breathing, and a dry but very troublesome cough, so that he could scarcely lie in his Bed or get the least Sleep." Morton saw him on the third day of his illness and considered it "to be plainly Peripneumonick" and ordered bleeding, fomentations and liniments externally with linctuses and "temperate juleps of antispasmodic waters" to be given internally. He was greatly puzzled, however, both by his own inability to control the fever and the patient's inability to produce sputum. The victim gradually grew weaker and "he dyed plainly of a consumption within the space of a Month or five weeks. Indeed I wondered very much at the obstinateness of the Pain and the difficulty of his Expectoration; and therefore, being directed by Hippocrates's Aphorism, I did foretell that a consumption from an Empyema would follow. But I never did so much as dream of the Original cause, to wit the Nails, which were slipt down into his lungs, before the Patient's Life was past all hope-The body being opened after he was dead, we found those three fatal Nails as it were buried together in one bed of Matter, a little below the divarication of the branches of the Windpipe, and the Tone of the Lungs universally impaired by the Matter which by degrees had crept all over them, and the very Membrane which covers the outside of the Lungs, corroded by the sharpness of the Matter; whereupon there came to be a continual dropping or distillation of purulent Phlegm into the cavity of the Breast out of which (to the best of my 
remembrance) I took at least six pints of this purulent liquor which when I saw, I no longer wondered at the obstinateness of the Pain, and the difficulty of his Expectoration, which accompanyed the Peripneumony. Nor did it seem strange that a Peripneumony caused in this manner should terminate in a fatal and such an Acute Consumption". 6

Phthisiologia throughout remains a completely clinical work being based entirely on Morton's own observations and experience. Apart from the rare mention of one of the aphorisms of Hippocrates he makes no reference to pre-existing or contemporary literature and his account of the various "consumptions" is clearly derived from what he has personally seen and studied. In reading the case histories appended to each chapter, compiled 300 years ago, it is impossible to withold one's admiration for his powers of clinical observation and deduction. In an era when not even the ancillary aid of a stethoscope was available to him and before Auenbrugger had discovered percussion his examination of the patient had to be confined to what his eyes could see with the occasional help of palpation. Thus equipped he made his diagnosis and, in reading his case histories, who is to say that he committed more diagnostic errors than the physicians of later generations.

The mystery of where Morton obtained his medical education remains unsolved. As an ousted Non-Conformist minister he could not have attended the flourishing School of Anatomy then located at Oxford, for attendance at the University was contingent on strict adherence to the Anglican form of worship. Trail, in his Gideon Delawne lecture in 1969 , suggested that "perhaps he was one of the many divines who, according to the poet George Herbert, then read medicine purely for the good of themselves and of their flock and so had commenced his studies while Vicar of Kinver."5 Some very tentative support for this view may be found in Mortons' own writings when he refers to "My dear Father who himself was a very skilful physician"6 yet it is known from the Dictionary of National Biography that his father was Robert Morton Minister of Bewdley Chapel in Worcestershire, while Munk's Roll confirms that he was the son of a clergyman. ${ }^{7}$ Is it possible than that as a young man he had access to medical textbooks in his father's library and did these so excite his interest that when the Church was barred to him he turned unhesitatingly to a career in medicine? But the author of Phthisiologia cannot have been entirely self-taught for in pursuing his postmortem studies he displays a knowledge of anatomy beyond that which he might have culled from a Galenic text, while his observations on the pathological changes which he encountered suggest that at some earlier stage in his career he had sat at the feet of a master.

In seeking an explanation of how this might have come about his association with the Netherlands must be taken into account. Clearly in the eight years which elapsed between his departure from Kinver and his reappearance at Oxford he must have visited Holland and remained there for some time since it is improbable that a transient visitor could have secured the patronage of the Prince of Orange. A clear reason for Morton's journey to Holland could be found in the existence at that period, within the University of Leyden, of what was probably the most famous medical school in Europe, a school which attracted numerous students from England and Scotland. No record of his attendance at Leyden has been found but it is so improbable that he could have lived in Holland and not attended Leyden or that he could have secured the royal cachet of approval without such attendance that the failure subsequently to trace his name in the records should not be given undue weight. If he attended at Leyden then the master at whose feet he would sit would have been Sylvius, at that period one of the brightest stars in the Leyden galaxy, remembered in history for his work on the morbid anatomy of phthisis and his elucidation of the importance of the tubercle. All this, of course, is entirely supposition but it does appear to be a reasonable theory to account for the eight blank years in Morton's life.

His path, thereafter, was smooth apart from the contretemps with James II and the College Charter and he clearly gained the confidence of his colleagues. $\mathrm{He}$ has been described as "a man of great gravity, calmness, sound principles, of no faction, an excellent preacher, of an upright life"2 to which might be added that he was a truly great clinician, a man honoured and respected by his peers and contemporaries as his memory and achievements have since been honoured by those generations of physicians who have succeeded him.

\section{References}

${ }^{1}$ Brownlee $J$. An investigation into the epidemiology of phthisis in Great Britain and Ireland. Med Res Comm London 1918:43.

2 Cummins SL. Tuberculosis in history. London: Bailliere, Tindall and Cox, 1949:6-7;32.

${ }^{3}$ Willis T. Practice of Physick. Phar II Sect I Chap VI. London, 1684:28.

1 Dictionary of National Biography.

5 Trail RR. Richard Morton (1637-98). Medical History 1970;14:166-76.

- Morton R. Phthisiologia. London: W and J Innys, 1720: $30-1 ; 49-51 ; 62 ; 81 ; 88 ; 126 ; 247-9 ; 118$.

7 Munk W. The Roll of the Royal College of Physicians of London. Second edition, London: Royal College of Physicians, 1878. 